\title{
Penerapan Metode Human Organization Technology (HOT-Fit Model) untuk Evaluasi Implementasi Aplikasi Sistem Informasi Persediaan (SIDIA) di Lingkungan Pemerintah Kota Bogor
}

\author{
Dedy Mulyadi ${ }^{1}$, Abdul Choliq ${ }^{2}$ \\ ${ }^{1}$ Program Studi Sistem Informasi STIKOM Binaniaga, Bogor, Indonesia \\ dedymulyadi@stikombinaniaga.ac.id \\ ${ }^{2}$ Badan Pengelolaan Keuangan dan Aset Daerah (BPKAD) Kota Bogor, Indonesia \\ kangmascholiq@gmail.com
}

\begin{abstract}
The SIDIA application is a desktop-based information system product built from the results of a change in Diklatpim IV project which functions to handle material data problems in the form of inventory, present information on the value and amount of inventory on the balance sheet of the Bogor City Government. This study uses the HOT-Fit Model method based on 4 dimensions, namely Human, Organization, Technology, and Net Benefits. Based on the results of the measurement of the level of success in evaluating the implementation of SIDIA applications in the Bogor City Government Environment, the lowest value is in the Organizational Structure variable which is equal to 3.64 and the Net Benefits variable is the highest average value of 4.01. Based on the results of the average value, the application of SIDIA is good, but in terms of service quality, the use of systems and organizational structures must be improved to make it better. In addition, a correlation measurement is carried out where the lowest correlation level is between Organizational Structure and Net Benefits, which is equal to 0.217 while the highest correlation factor is between Information Quality and User Satisfaction, which is 0.835. In this study also measured the level of influence where the lowest level of influence is the Quality of Service on Net Benefits which is equal to $1.1 \%$ while the factor that has the highest level of influence is the Quality of Information on Net Benefits which is $35.4 \%$.
\end{abstract}

Keyword: HOT-Fit model, evaluation, means, linear correlation, determination coefficient.

\begin{abstract}
ABSTRAK
Aplikasi SIDIA merupakan produk sistem informasi berbasis desktop yang dibangun dari hasil proyek perubahan Diklatpim IV yang berfungsi untuk menangani masalah data materiil berupa persediaan, menyajian informasi nilai dan jumlah persediaan pada neraca Pemerintah Kota Bogor. Penelitian ini menggunakan metode HOT-Fit Model berdasarkan 4 dimensi yaitu Human (manusia), Organization (organisasi), Technology (teknologi) dan Net Benefits (keuntungan). Berdasarkan hasil pengukuran tingkat keberhasilan pada evaluasi implementasi aplikasi SIDIA di Lingkungan Pemerintah Kota Bogor, nilai terendah terdapat pada variabel Struktur Organisasi yaitu sebesar 3,64 dan variabel Net Benefits merupakan yang paling tinggi nilai rata-ratanya yaitu sebesar 4,01. Berdasarkan hasil nilai rata-rata, aplikasi SIDIA sudah baik akan tetapi dari sisi kualitas layanan, penggunaan sistem dan struktur organisasi harus dilakukan peningkatan agar lebih baik. Selain itu dilakukan pengukuran korelasi dimana faktor yang paling rendah tingkat korelasinya adalah antara Struktur Organisasi dengan Net Benefits yaitu sebesar 0,217 sedangkan Faktor yang paling tinggi tingkat korelasinya adalah antara Kualitas Informasi dengan Kepuasan Pengguna yaitu sebesar 0,835. Dalam penelitian ini juga dilakukan pengukuran tingkat pengaruh dimana faktor yang paling rendah tingkat pengaruhnya yaitu Kualitas Layanan terhadap Net Benefits yaitu sebesar 1,1 \% sedangkan faktor yang paling tinggi tingkat pengaruhnya adalah Kualitas Informasi terhadap Net Benefits yaitu sebesar $35,4 \%$.
\end{abstract}

Kata kunci: HOT-Fit model, evaluasi, mean, korelasi linier, koefisien determinasi. 


\section{PENDAHULUAN}

\section{Latar Belakang}

Di zaman modern ini tidak dapat dipungkiri bahwa teknologi informasi menjadi salah satu sumber daya utama pada suatu organisasi yang memegang peranan penting untuk meningkatkan daya saing serta pelayanan yang optimal. Oleh sebab itu, setiap organisasi baik pemerintah maupun swasta mencoba untuk menerapkan teknologi informasi agar dapat meningkatkan efektifitas dan efisiensi dalam proses bisnis maupun pelayanan, hal ini bertujuan agar mampu memberikan nilai tambah yaitu berupa keunggulan kompetitif. Tidak terkecuali pada organisasi pemerintahan yang pada dasarnya perkembangan-perkembangan teknologi informasi yang terjadi pada era modern ini sangat berperan dalam penyelenggaraan organisasi pemerintahan.

Dalam pengertian yang sederhana teknologi informasi adalah sebuah sarana telekomunikasi yang menggunakan sistem perangkat lunak dan keras dalam komputer untuk menyimpan dan menyampaikan sebuah informasi penting kepada orang lain. Jadi, pada hakekatnya teknologi informasi merupakan fasilitas yang berfungsi sebagai sarana guna meningkatkan kualitas layanan informasi yang lebih mudah untuk semua orang. Sistem Informasi yang merupakan bagian dari Teknologi informasi merupakan bagian yang sangat penting dalam penggunaan teknologi informasi. Pemanfaatan sistem informasi dalam suatu organisasi pemerintahan dapat membantu memberikan kemudahan bagi organisasi tersebut dalam menjalankan pelayanannya.

Evaluasi sistem informasi secara sederhana adalah merupakan suatu pengujian terhadap pengendalian infrastruktur sistem informasi. Dengan evaluasi tersebut, pencapaian aktifitas atau kegiatan atas penyelenggaraan suatu sistem informasi dapat segera diketahui dan tindakan lebih lanjut dapat direncanakan guna memperbaiki kinerja penerapannya. Evaluasi dilakukan juga untuk menentukan apakah sistem informasi tersebut berjalan dengan baik dalam rangka menunjang proses peningkatan kualitas pelayanan dalam organisasi ataukah tidak.

Aplikasi Sistem Informasi Persediaan (SIDIA) adalah salah satu produk sistem informasi berbasis desktop yang dibuat dalam rangka proyek perubahan Diklatpim IV pegawai di lingkungan Pemerintah Kota Bogor untuk menangani masalah data materiil berupa persediaan dan menyajikan informasi sesuai dengan Peraturan Menteri Dalam Negeri Nomor 19 Tahun 2016 tentang Pedoman Pengelolaan Barang Milik Daerah (BMD) dan Peraturan Wali Kota Bogor Nomor 53 Tahun 2017 tentang Pedoman Pengelolaan Barang Persediaan di Lingkungan Pemerintah Kota Bogor. Namun di tahun 2017 sampai dengan pertengahan tahun 2018 belum semua pengurus barang dalam menyampaikan laporan jumlah dan nilai persediaan menggunakan aplikasi SIDIA, sebagian besar masih menyampaikan secara manual bukan output (keluaran) dari aplikasi.

Pemerintah Kota Bogor sangat mengharapkan bahwa aplikasi ini dapat diimplementasikan kepada pengguna di setiap Perangkat Daerah dalam menyajikan nilai persediaan. Untuk itu, implementasi merupakan tolak ukur bagi organisasi untuk menentukan apakah sistem tersebut berjalan dengan baik. Dengan melakukan evaluasi lebih dini, organisasi dapat mengantisipasi kemungkinan buruk yang bisa terjadi dan meminimalkan dampak negatif yang timbul. Penelitian ini kemudian dilakukan untuk mengevaluasi aspek Human Organizatioan Technology (HOT-Fit Model) yang mempengaruhi tingkat keberhasilan terhadap implementasi aplikasi Sistem Informasi Persediaan (SIDIA) berbasis desktop. Implementasi aplikasi diukur berdasarkan empat komponen yaitu komponen manusia (Human), komponen organisasi (Organization) dan komponen teknologi (Technology) dan manfaat (Net Benefits). Kecenderungan kelayakan, keberhasilan atau kegagalan implementasi terhadap aplikasi melalui kegiatan survey diharapkan dapat memberikan masukan / rekomendasi untuk menentukan kebijakan dalam mengelola, memanfaatkan dan mengembangkan aplikasi SIDIA tersebut di kemudian hari.

Pengukuran tingkat keberhasilan implementasi aplikasi SIDIA ini dapat menggunakan metode Human Organization Technology (HOT-Fit Model). Model ini dipilih karena dianggap 
mampu menjelaskan evaluasi secara konfrehensif dengan pendekatan komponen inti sistem informasi. Komponen HOT-Fit Model yang digunakan dalam penelitian ilmiah ini adalah human (Penggunaan Sistem, Kepuasan Pengguna), organization (Struktur Organisasi), technology (Kualitas Sistem, Kualitas Informasi, Kualitas Layanan) dan kesesuaian ketiga faktor tersebut mempengaruhi manfaat (net benefits). Penelitian yang dilakukan oleh Nurpauliani Dewi dan Syaifullah tentang Analisis Penerapan Fire Report Online System (FROS) Menggunakan Metode HOT-Fit (Studi Kasus: PT Arara Abadi), keberhasilan dari penerapan sistem FROS adalah penggunaan sistem dapat diterapkan secara maksimal, dilakukan pelatihan rutin terhadap pengguna sistem FROS, disediakan ahli IT untuk memantau perkembangan sistem dan kualitas sistem serta kualitas informasi lebih ditingkatkan. Kemudian penelitian yang dilakukan oleh Kadarsih, Pujianto dan Muhajir Arafat tentang Evaluasi Digital Library AMIK AKMI Baturaja Menggunakan HOT-Fit Model, diketahui bahwa hubungan antara ketiga variabel yakni Human, Organization dan Technology memiliki hubungan yang kuat, dan saling mempengaruhi antara variabel satu dengan variabel lainnya, namun masih dibutuhkan perbaikan dari beberapa hal yang menjadi kelemahan digital library AMIK AKMI untuk peningkatan kepuasan pengguna terhadap layanan yang diberikan. Berdasarkan penelitian tersebut kemudian menjadi bahan pertimbangan bahwa metode HOT-Fit dapat digunakan untuk evaluasi implementasi aplikasi SIDIA di lingkungan Pemerintah Kota Bogor.

\section{Permasalahan}

Badan Pengelolaan Keuangan dan Aset Daerah (BPKAD) Kota Bogor bertanggungjawab kepada Pemerintah Kota Bogor untuk menyusun dan menyajikan laporan nilai dan jumlah persediaan pada neraca Pemerintah Kota Bogor yang dihimpun dari perangkat daerah yang terdapat di lingkungan Pemerintah Kota Bogor. Untuk mempermudah tanggung jawab tersebut, melalui proyek perubahan Diklatpim IV dibangun sebuah aplikasi yang dapat membantu dalam menyusun laporan nilai dan jumlah persediaan yaitu Sistem Informasi Persediaan (SIDIA).

Dalam rangka menerapkan aplikasi SIDIA pada perangkat daerah di lingkungan Pemerintah Kota Bogor, sosialisasi dan bimbingan teknis (Bimtek) telah dilaksanakan kepada pengurus barang yang mempunyai tugas pokok menyusun laporan persediaan. Aplikasi SIDIA menyajikan semua laporan yang perlukan oleh pengurus barang yaitu daftar pengadaan barang, buku penerimaan barang, buku pengeluaran barang, buku barang pakai habis, laporan semester, kartu barang, kartu persediaan barang dan laporan rekap barang. Banyaknya laporan yang harus dibuat oleh pengurus barang tentu akan menyita banyak waktu dan membutuhkan ketelitian yang cukup tinggi jika semua laporan tersebut dikerjakan secara manual apalagi jika barang persediaan yang menjadi tanggung jawab pengurus barang cukup banyak. Jika laporan-laporan tersebut tidak dikerjakan akan menjadi temuan dari Tim Pemeriksa seperti tidak tertib administrasi atau pengerjaannya tidak sesuai dengan ketentuan atau peraturan yang berlaku. Dengan menggunakan aplikasi SIDIA, pengurus barang hanya melakukan entry data pengadaan, penerimaan dan pengeluaran kemudian seluruh laporan yang diperlukan akan secara otomatis dibuat oleh aplikasi SIDIA sehingga pengurus barang dapat menghemat waktu dan laporan yang disajikan sesuai dengan peratuan yang berlaku.

1. Identifikasi masalah

Berdasarkan permasalahan di atas, maka identifikasi masalah yang dapat diangkat diantaranya:

a. Belum diketahui korelasi / hubungan sumber daya manusia (Human) pada implementasi aplikasi SIDIA di lingkungan Pemerintah Kota Bogor di evaluasi menggunakan metode Human, Organization, Technologi (HOT-Fit Model).

b. Belum diketahui korelasi / hubungan organisasi (Organization) pada implementasi aplikasi SIDIA di lingkungan Pemerintah Kota Bogor dievaluasi menggunakan metode Human, Organization, Technologi (HOT-Fit Model).

c. Belum diketahui korelasi / hubungan teknologi (Technology) pada implementasi aplikasi SIDIA di lingkungan Pemerintah Kota Bogor dievaluasi menggunakan metode Human, Organization, Technologi (HOT-Fit Model). 
d. Belum diketahui korelasi / hubungan manfaat (net benefits) pada implementasi aplikasi SIDIA di lingkungan Pemerintah Kota Bogor dievaluasi menggunakan metode Human, Organization, Technologi (HOT-Fit Model).

2. Rumusan masalah

Agar dapat membantu dalam mengatasi masalah, sehingga diketahui tingkat keberhasilan implementasi aplikasi SIDIA di lingkungan Pemerintah Kota Bogor. Maka rumusan masalah untuk mengatasi masalah yang terjadi adalah:

a. Pernyataan masalah (Problem Statement)

Belum diketahui tingkat keberhasilan implementasi aplikasi SIDIA di lingkungan Pemerintah Kota Bogor sebagai penyedia informasi.

b. Pertanyaan penelitian (Research Question)

Bagaimana tingkat keberhasilan implementasi aplikasi SIDIA di lingkungan Pemerintah Kota Bogor dievaluasi dengan menggunakan metode HOT-Fit Model?

\section{METODE PENELITIAN}

"Penelitian adalah usaha untuk menemukan, mengembangkan, dan menguji kebenaran suatu pengetahuan, usaha mana dilakukan dengan menggunakan metode ilmiah" (Amos Neolaka, 2016, p.2). Untuk dapat menghasilkan penelitian yang baik, maka dibutuhkan desain penelitian untuk menunjang dan memberikan hasil penelitian yang sistematik. Desain penelitian adalah semua proses yang diperlukan dalam perencanaan dan pelaksanaan penelitian, yang membantu penelitian dalam pengumpulan dan menganalisis data.

\section{Variabel Penelitian}

Variabel adalah suatu atribut atau sifat atau nilai dari orang, obyek atau kegiatan yang mempunyai variasi tertentu yang ditetapkan oleh peneliti untuk dipelajari dan kemudian ditarik kesimpulannya (Sugiyono, 2017, p.39). Dalam penelitian ini variabel yang digunakan untuk pertanyaan kuisioner yaitu data kuisioner yang disebar kepada user atau pengguna aplikasi SIDIA. Berdasarkan identifikasi masalah maka penelitian ini menggunakan metode Human Organization Technology (HOT-Fit) Model dengan 4 dimensi, yaitu :

\section{Human (Manusia)}

2. Organization (Organisasi)

3. Technology (Teknologi)

4. Net Benefits (Manfaat)

\section{Sumber Data}

Sumber data dalam penelitian adalah subyek dari mana data dapat diperoleh. Berikut data yang akan menjadi acuan dalam pembuatan penelitian ini adalah kuisioner. Angket / kuisioner merupakan daftar pertanyaan / pernyataan yang diberikan kepada orang lain dengan maksud agar orang yang diberi tersebut bersedia memberikan respons sesuai dengan permintaan pengguna (Suharsimi Arikunto, 2016, pp. 102 - 103). Data dalam penelitian ini yang digunakan adalah data primer. Data primer adalah yang langsung diperoleh dari sumber data pertama di lokasi penelitian atau obyek penelitian. Data ini diperoleh dengan menyebarkan kuisioner (angket) kepada seluruh pengguna aplikasi SIDIA di lingkungan Pemerintah Kota Bogor.

Populasi adalah wilayah generalisasi yang terdiri atas obyek atau subyek yang mempunyai kualitas dan karakteristik tertentu yang ditetapkan oleh peneliti untuk dipelajari kemudian ditarik kesimpulannya (Sugiyono, 2017, p.80). Pengguna aplikasi sebagai populasi dalam penelitian ini adalah pegawai negeri sipil (PNS) di Lingkungan Pemerintah Kota Bogor yang berjumlah 38 orang 
yang merupakan pengurus barang yang bertugas sebagai user aplikasi SIDIA ditingkat Perangkat Daerah.

\section{Pengumpulan Data}

Pengumpulan data yang akan dilakukan dengan cara menyebar kuisioner kepada responden. Kuisioner atau angket merupakan cara pengumpulan data dengan menggunakan daftar isian tertutup, daftar pertanyaan telah disiapkan dan disusun dengan baik sehingga responden hanya akan mengisi dengan mudah dan cepat.

\section{Metode Analisis Data}

Metode analisis data dalam peneliatian ini dilakukan dengan beberapa tahap pengujian, diataranya sebagai berikut:

\section{Mean / Rata-Rata}

Rata-rata (Mean) adalah hasil penjumlahan nilai-nilai anggota sebuah kelompok $\left(\sum \mathrm{X}_{\mathrm{i}}\right)$ dibagi jumlah anggota kelompok tersebut. Pengujian yang digunakan untuk mengukur tingkat keberhasilan implementasi aplikasi SIDIA yaitu menggunakan metode statistik mean / rata-rata. Alat ukur yang akan digunakan untuk menganalisa data dengan metode statistik digunakan adalah:

$$
\bar{x}=\frac{\sum X_{i}}{n}
$$

Keterangan:

$$
\begin{array}{ll}
\mathrm{X} & =\text { Nilai Skor Rata-Rata } \\
\sum x_{i} & =\text { Jumlah skor } \\
\mathrm{N} & =\text { Jumlah responden }
\end{array}
$$

Penghitungan mean / rata-rata dalam pengujian ini dilakukan dengan cara menjumlahkan seluruh nilai data kelompok sampel / pengamatan, kemudian dibagi jumlah / banyaknya sampel tersebut.

Rentang penilaian rata-rata dan kategorinya untuk pemetaan tingkat keberhasilan implementasi aplikasi SIDIA. Untuk menentukan rentang penilaian rata-rata kita dapat menggunakan rumus:

$\frac{\text { skor tertinggi }- \text { skor terendah }}{\text { jumlah jawaban }}=\frac{5-1}{5}=\frac{4}{5}=0,8$

Berdasarkan hasil perhitungan di atas maka diperoleh kriteria seperti pada tabel 1. berikut:

Tabel 1. Rentang Penilaian Rata-Rata

\begin{tabular}{|c|c|}
\hline Rentang Nilai Rata-Rata & Kategori Penilaian \\
\hline $4,51-5,00$ & Sangat Baik \\
\hline $3,61-4,50$ & Baik \\
\hline $2,71-3,60$ & Sedang \\
\hline $1,81-2,70$ & Kurang \\
\hline $1,00-1,80$ & Sangat Kurang \\
\hline
\end{tabular}

2. Korelasi Linier

Statistika ini diartikan sebagai metode pengetahuan yang berhubungan dengan cara-cara penafsiran dan penarikan kesimpulan berdasarkan kumpulan data yang telah diperoleh sebelumnya melalui survey dan penganalisaan yang dilakukan melalui aturan-aturan dan prosedur-prosedur tertentu. 
Berikut rumus dari statistika korelasi linier:

$$
r=\frac{n \sum_{i=1}^{n} x_{i} y_{i}-\left(\sum_{i=1}^{n} x_{i}\right)\left(\sum_{i=1}^{n} y_{i}\right)}{\sqrt{\left[n \sum_{i=1}^{n} x_{i}^{2}-\left(\sum_{i=1}^{n} x_{i}\right)^{2}\right]\left[n \sum_{i=1}^{n} y_{i}^{2}-\left(\sum_{i=1}^{n} y_{i}\right)^{2}\right]}}
$$

Keterangan:

$$
\begin{array}{ll}
\mathrm{r} & =\text { koefisien korelasi linear } \\
\mathrm{n} & =\text { jumlah responden } \\
\mathrm{x}_{\mathrm{i}} & =\text { skor total indikator } \mathrm{X} \text { dari responden ke-i } \\
\mathrm{y}_{\mathrm{i}} & =\text { skor total indikator } \mathrm{Y} \text { dari responden ke-i } \\
\mathrm{i} & =1,2,3, \ldots, \mathrm{n}
\end{array}
$$

Pendekatan kriteria HOT-Fit Model dengan perhitungan korelasi linier dipilih karena dapat mewakili dan menghasilkan suatu penilaian terhadap kriteria / indikator. Metode ini digunakan untuk mencari korelasi antara variabel Human, Organization, Technology dan kesesuaian diantara ketiga komponen tersebut mempengaruhi net benefits.

Pedoman interpretasi tingkat kekuatan hubungan sebagaimana yang dikemukakan Sugiyono (2011 : 148) sebagai berikut:

Tabel 2. Interpretasi Tingkat Kekuatan Hubungan

\begin{tabular}{|c|l|}
\hline $\begin{array}{c}\text { Besarnya "r" } \\
\text { Product Moment }\left(\mathrm{r}_{\mathrm{xy}}\right)\end{array}$ & \multicolumn{1}{c|}{ Interpretasi } \\
\hline $0,000-0,199$ & Sangat lemah atau sangat rendah \\
$0,200-0,399$ & Lemah atau rendah \\
$0,400-0,599$ & Sedang atau cukup \\
$0,600-0,799$ & Kuat atau tinggi \\
$0,800-1,000$ & Sangat kuat atau sangat tinggi \\
\hline
\end{tabular}

3. Koefisien Determinasi

"Koefisien determinasi adalah kadar kontribusi variabel bebas terhadap variabel terikat $\left(r^{2}\right)$ " (Amos Neolaka, 2016, p.130). Koefisien determinasi dilambangkan dengan $r^{2}$. Nilai ini menyatakan proporsi variasi keseluruhan dalam nilai variabel dependen yang dapat diterangkan atau diakibatkan oleh hubungan linear dengan nilai variabel independen.

Koefisien determinasi dari variabel $\mathrm{X}$ dan variabel $\mathrm{Y}$ menggambarkan seberapa besar pengaruh perubahan nilai-nilai X terhadap perubahan nilai-nilai Y (Dedy Mulyadi, 2014, pp. 1415). Koefisien determinasi dirumuskan sebagai:

$\mathrm{KD}=(\mathrm{r})^{2} .100 \%$

dimana:

$\mathrm{KD}=$ Koefisien Determinasi.

$\mathrm{r} \quad=$ Koefisien Korelasi antara Variabel X dan Variabel Y. 


\section{HASIL DAN PEMBAHASAN}

\section{Hasil Penelitian}

1. Pengukuran Tingkat Keberhasilan dengan Mean / Rata-Rata.

Rata-rata (Mean) adalah hasil penjumlahan nilai-nilai anggota sebuah kelompok $\left(\sum \mathrm{X}_{\mathrm{i}}\right)$ dibagi jumlah anggota kelompok tersebut. Pengujian yang digunakan untuk mengukur tingkat keberhasilan implementasi aplikasi SIDIA yaitu menggunakan metode statistik mean / rata-rata. Alat ukur yang digunakan untuk menganalisa data dengan metode statistik digunakan adalah:

$$
\bar{x}=\frac{\sum X_{i}}{n}
$$

Keterangan:

$\mathrm{X}=$ Nilai Skor Rata-Rata

$\sum x_{i}=$ Jumlah skor

$\mathrm{N}=$ Jumlah responden

Perhitungan nilai rata-rata dan interpretasinya dari implementasi aplikasi SIDIA sebagaimana tersaji dalam tabel berikut:

Tabel 3. Hasil nilai rata-rata dari setiap parameter HOT-Fit Model

\begin{tabular}{|c|c|c|c|}
\hline No & Parameter & Rata-rata & Kategori penilaian \\
\hline 1 & Kualitas Sistem & 3.79 & Baik \\
\hline 2 & Kualitas Informasi & 3,92 & Baik \\
\hline 3 & Kualitas Layanan & 3,65 & Baik \\
\hline 4 & Penggunaan Sistem & 3,66 & Baik \\
\hline 5 & Kepuasan Pengguna & 3,88 & Baik \\
\hline 6 & Struktur Organisasi & 3,64 & Baik \\
\hline 7 & Net Benefits & 4,01 & Baik \\
\hline
\end{tabular}

2. Pengukuran Tingkat Keberhasilan dengan Koefisian Korelasi.

a. Korelasi Variabel Kualitas Sistem dengan Penggunaan Sistem:

Berdasarkan hasil output SPSS diperoleh koefisien (r) antara variabel Kualitas Sistem dengan variabel Penggunaan Sistem sebesar 0,721 dan nilai signifikansi sebesar 0,000 .

Tabel 4. Korelasi Kualitas Sistem dengan Penggunaan Sisitem 
Correlations

\begin{tabular}{|ll|r|r|}
\hline & & $\begin{array}{c}\text { kualitas_siste } \\
\text { m }\end{array}$ & $\begin{array}{c}\text { penggunaan_ } \\
\text { sistem }\end{array}$ \\
\hline kualitas_sistem & Pearson Correlation & 1 & $.721^{\text {"1 }}$ \\
& Sig. (2-tailed) & & .000 \\
& $\mathrm{~N}$ & 38 & 38 \\
\hline penggunaan_sistem & Pearson Correlation & $.721^{\prime \prime}$ & 1 \\
& Sig. (2-tailed) & .000 & 38 \\
& $\mathrm{~N}$ & 38 & 3 \\
\hline
\end{tabular}

**. Correlation is significant at the 0.01 level (2-tailed).

Pengujian menggunakan uji dua sisi dimana tingkat signifikansi $\alpha=1 \%$ dari hasil output SPSS tersebut. Berdasarkan kriteria pengujian, dimana korelasi tidak signifikan jika signifikansi > 0,01 atau korelasi signifikan jika signifikansi < 0,01. Berdasarkan hasil uji tersebut nilai signifikansi sebesar $0,000<0.01$ maka dapat disimpulkan bahwa terdapat hubungan secara signifikan antara kualitas sistem terhadap penggunaan sistem.

b. Korelasi dan hipotesis antar variabel lainnya sebagaimana tersaji dalam tabel berikut:

Tabel 5. Hasil Koefisien Korelasi dan Pengujian Hipotesisnya

\begin{tabular}{|c|c|c|c|c|c|}
\hline No & Konstruk & $\begin{array}{c}\text { Koefisien } \\
\text { Korelasi } \\
(\mathrm{r})\end{array}$ & $\begin{array}{c}\text { Tingkat } \\
\text { Korelasi }\end{array}$ & $\begin{array}{c}\text { Nilai } \\
\text { Signifikansi }\end{array}$ & Kesimpulan \\
\hline 1 & $\begin{array}{c}\text { Kualitas Sistem } \\
\text { terhadap Penggunaan } \\
\text { Sistem }\end{array}$ & 0,721 & Kuat & 0,000 & $\begin{array}{c}\text { Terdapat } \\
\text { hubungan }\end{array}$ \\
\hline 2 & $\begin{array}{c}\text { Kualitas Sistem } \\
\text { terhadap Kepuasan } \\
\text { Pengguna }\end{array}$ & 0,681 & Kuat & 0,000 & $\begin{array}{c}\text { Terdapat } \\
\text { hubungan }\end{array}$ \\
\hline 3 & $\begin{array}{c}\text { Kualitas Informasi } \\
\text { terhadap Penggunaan } \\
\text { Sistem }\end{array}$ & 0,440 & Sedang & 0,006 & $\begin{array}{c}\text { Terdapat } \\
\text { hubungan }\end{array}$ \\
\hline 5 & $\begin{array}{c}\text { Kualitas Informasi } \\
\text { terhadap Kepuasan } \\
\text { Pengguna }\end{array}$ & 0,835 & $\begin{array}{c}\text { Sangat } \\
\text { Kuat }\end{array}$ & 0,000 & $\begin{array}{c}\text { Terdapat } \\
\text { hubungan }\end{array}$ \\
\hline 6 & $\begin{array}{c}\text { Kualitas Layanan } \\
\text { terhadap Penggunaan } \\
\text { Sistem }\end{array}$ & 0,623 & Kuat & 0,000 & $\begin{array}{c}\text { Terdapat } \\
\text { hubungan }\end{array}$ \\
\hline 7 & $\begin{array}{c}\text { Kualitas Layanan } \\
\text { terhadap Kepuasan } \\
\text { Pengguna }\end{array}$ & 0,513 & Kuat & 0,001 & $\begin{array}{c}\text { Terdapat } \\
\text { hubungan }\end{array}$ \\
\hline $\begin{array}{c}\text { Kepuasan Pengguna } \\
\text { terhadap Penggunaan } \\
\text { Sistem }\end{array}$ & $\begin{array}{c}\text { Struktur Organisasi } \\
\text { terhadap Kepuasan } \\
\text { Pengguna }\end{array}$ & 0,587 & Sedang & 0,000 & $\begin{array}{c}\text { Terdapat } \\
\text { hubungan }\end{array}$ \\
\hline
\end{tabular}


Jurnal Ilmiah Teknologi - Informasi dan Sains (TeknoIS)

Volume 7 Nomor 2 Bulan November 2017 Hal. 1-12

p-ISSN : 2087-3891 dan e-ISSN : 2597-8918

\begin{tabular}{|c|c|c|c|c|c|}
\hline No & Konstruk & $\begin{array}{c}\text { Koefisien } \\
\text { Korelasi } \\
(\mathrm{r})\end{array}$ & $\begin{array}{c}\text { Tingkat } \\
\text { Korelasi }\end{array}$ & $\begin{array}{c}\text { Nilai } \\
\text { Signifikansi }\end{array}$ & Kesimpulan \\
\hline 9 & $\begin{array}{c}\text { Penggunaan Sistem } \\
\text { terhadap Net Benefits }\end{array}$ & 0,343 & Lemah & 0,035 & $\begin{array}{c}\text { Tidak } \\
\text { terdapat } \\
\text { hubungan }\end{array}$ \\
\hline 10 & $\begin{array}{c}\text { Kepuasan Pengguna } \\
\text { terhadap Net Benefits }\end{array}$ & 0,574 & Sedang & 0,000 & $\begin{array}{c}\text { Terdapat } \\
\text { hubungan }\end{array}$ \\
\hline 11 & $\begin{array}{c}\text { Struktur Organisai } \\
\text { terhadap Net Benefits }\end{array}$ & 0,209 & Lemah & 0,207 & $\begin{array}{c}\text { Tidak } \\
\text { terdapat } \\
\text { hubungan }\end{array}$ \\
\hline 12 & $\begin{array}{c}\text { Kualitas Sistem } \\
\text { terhadap Struktur } \\
\text { Organisasi }\end{array}$ & 0,622 & Kuat & 0,000 & $\begin{array}{c}\text { Terdapat } \\
\text { hubungan }\end{array}$ \\
\hline 13 & $\begin{array}{c}\text { Kualitas Informasi } \\
\text { terhadap Struktur } \\
\text { Organisasi }\end{array}$ & 0,439 & Sedang & 0,006 & $\begin{array}{c}\text { Terdapat } \\
\text { hubungan }\end{array}$ \\
\hline 14 & $\begin{array}{c}\text { Kualitas Layanan } \\
\text { terhadap Struktur } \\
\text { Organisasi }\end{array}$ & 0,732 & Kuat & 0,000 & $\begin{array}{c}\text { Terdapat } \\
\text { hubungan }\end{array}$ \\
\hline
\end{tabular}

3. Koefisien Determinasi

a. Perhitungan Koefisien Determinasi variabel Kualitas Sistem terhadap Net Benefits

$$
\begin{aligned}
\mathrm{KD} & =(0,493)^{2} \cdot 100 \% \\
& =0,243 \cdot 100 \% \\
& =24,3 \%
\end{aligned}
$$

Hasil pengukuran koefisien determinasi menunjukkan bahwa besarnya kontribusi dari variabel Kualitas Sistem terhadap perubahan nilai pada variabel Net Benefits adalah sebesar $24,3 \%$.

b. Hasil perhitungan Koefisien Determinasi antar variabel lainnya sebagaimana tersaji dalam tabel berikut:

Tabel 6. Hasil Perhitungan Koefisien Determinasi

\begin{tabular}{|c|c|c|}
\hline No & Konstruk & Tingkat Pengaruh \\
\hline 1 & Kualitas Sistem terhadap Net Benefits & $24,3 \%$ \\
\hline 2 & Kualitas Informasi dengan Net Benefits & $35,4 \%$ \\
\hline 3 & Kualitas Layanan dengan Net Benefits & $1,1 \%$ \\
\hline 4 & Kepuasan Pengguna dengan Net Benefits & $32,9 \%$ \\
\hline 5 & Struktur Organisasi dengan Net Benefits & $4,4 \%$ \\
\hline
\end{tabular}

\section{Pembahasan}

Hasil dari analisa data yang telah dilakukan adalah sebagai berikut:

1. Rata-Rata 
Berdasarkan hasil pengukuran tingkat keberhasilan pada evaluasi implementasi aplikasi SIDIA di Lingkungan Pemerintah Kota Bogor, nilai terendah terdapat pada variabel Struktur Organisasi yaitu sebesar 3,64 dan variabel Net Benefits merupakan yang paling tinggi nilai rataratanya yaitu sebesar 4.01. Berdasarkan hasil nilai rata-rata pada tabel 4. aplikasi SIDIA sudah baik akan tetapi dari sisi kualitas layanan, penggunaan sistem dan struktur organisasi harus dilakukan peningkatan agar lebih baik. Ada pun peningkatan tersebut dapat berupa respon yang cepat, memberikan jaminan layanan, memiliki sikap peduli / empati dan menyelesaikan masalah jika user memerlukan bantuan, mendorong user agar selalu menggunakan aplikasi SIDIA untuk mempermudah penyusunan laporan persediaan serta organisasi mempertimbangkan latar belakang pendidikan, memberikan pelatihan, memiliki komunikasi yang baik, mampu mengatasi setiap konflik pengelola aplikasi SIDIA.

2. Koefisien Korelasi Linier

Uji korelasi bertujuan untuk menguji hubungan antara dua variabel yang dapat dilihat dengan tingkat signifikan. Jika ada hubungannya maka akan dicari seberapa kuat hubungan

Dalam penelitian ini faktor yang paling rendah tingkat korelasinya adalah antara Struktur Organisasi dengan Net Benefits yaitu sebesar 0,217. Faktor yang paling tinggi tingkat korelasinya adalah antara Kualitas Informasi dengan Kepuasan Pengguna yaitu sebesar 0,835.

Berdasarkan tabel 5. dapat diketahui bahwa kualitas sistem, kualitas informasi dan kualitas layanan berhubungan dengan penggunaan sistem, kepuasan pengguna dan struktur organisasi, hal ini berarti semakin tinggi kualitas sistem, kualitas informasi dan kualitas layanan aplikasi SIDIA, maka akan semakin meningkat pula penggunaan sistem, kepuasan pengguna, dan peran struktur organisasi terhadap aplikasi SIDIA. Kepuasan pengguna berhubungan dengan penggunaan sistem dan net benefits, hal ini berarti semakin tinggi kepuasan pengguna aplikasi SIDIA maka akan semakin meningkat pula penggunaan sisitem dan manfaat (net benefits) yang didapatkan dari aplikasi SIDIA. Struktur organisasi berhubungan dengan kepuasan pengguna yang berarti bahwa semakin tinggi peranan struktur organisasi maka semakin meningkat pula kepuasan pengguna terhadap aplikasi SIDIA. Penggunaan sistem dan struktur organisasi tidak berpengaruh terhadap net benefits, hal ini berarti penggunaan sistem dan struktur organisasi tidak memiliki pengaruh terhadap net benefits.

3. Koefisien Determinasi

Dalam penelitian ini faktor yang paling rendah tingkat pengaruhnya yaitu Kualitas Layanan terhadap Net Benefits yaitu sebesar 1,1\%. Faktor yang paling tinggi tingkat pengaruhnya adalah Kualitas Informasi terhadap Net Benefits yaitu sebesar 35,4\%. Tabel hasil perhitungan koefisien determinasi antar setiap konstruk dapat dilihat pada tabel 6 .

\section{KESIMPULAN DAN SARAN}

\section{Kesimpulan}

Dengan adanya pendekatan HOT-Fit Model yang terdiri dari variabel Kualitas Sistem, Kualitas Informasi, Kualitas Layanan, Penggunaan Sistem, Kepuasan Pengguna, Struktur Organisasi, dan Net Benefits dapat diketahui tingkat keberhasilan implementasi aplikasi SIDIA di Lingkungan Pemerintah Kota Bogor.

Berdasarkan hasil penelitian, maka dapat disimpulkan hasil korelasi pengukuran tingkat keberhasilan implementasi aplikasi SIDIA adalah sebagai berikut:

1. Kepuasan pengguna berhubungan dengan penggunaan sistem dan net benefits.

2. Struktur organisasi berhubungan dengan kepuasan pengguna.

3. Kualitas sistem, kualitas informasi dan kualitas layanan berhubungan dengan penggunaan sistem, kepuasan pengguna dan struktur organisasi. 
4. Penggunaan sistem dan struktur organisasi tidak berpengaruh terhadap net benefits.

Hasil pengukuran tingkat keberhasilan implementasi aplikasi SIDIA adalah sebagai berikut:

1. Keberhasilan implementasi aplikasi SIDIA berdasarkan kualitas sistem mempunyai nilai rata-rata yaitu 3.79 yang berarti baik.

2. Keberhasilan implementasi aplikasi SIDIA berdasarkan kualitas informasi mempunyai nilai ratarata yaitu 3.92 yang berarti baik.

3. Keberhasilan implementasi aplikasi SIDIA berdasarkan kualitas layanan mempunyai nilai ratarata yaitu 3.65 yang berarti baik.

4. Keberhasilan implementasi aplikasi SIDIA berdasarkan penggunaan sistem nilai rata-rata yaitu 3.66 yang berarti baik.

5. Keberhasilan implementasi aplikasi SIDIA berdasarkan kepuasan pengguna mempunyai nilai rata-rata yaitu 3.88 yang berarti baik.

6. Keberhasilan implementasi aplikasi SIDIA berdasarkan struktur organisasi mempunyai nilai ratarata yaitu 3.64 yang berarti baik.

7. Keberhasilan implementasi aplikasi SIDIA berdasarkan net benefits mempunyai nilai rata-rata yaitu 4.01 yang berarti baik. berikut:

Hasil pengukuran tingkat pengaruh keberhasilan implementasi aplikasi SIDIA adalah sebagai

1. Tingkat pengaruh keberhasilan implementasi aplikasi SIDIA berdasarkan kualitas sistem dengan net benefits yaitu sebesar $24,3 \%$.

2. Tingkat pengaruh keberhasilan implementasi aplikasi SIDIA berdasarkan kualitas informasi dengan net benefits yaitu sebesar $35,4 \%$.

3. Tingkat pengaruh keberhasilan implementasi aplikasi SIDIA berdasarkan kualitas layanan dengan net benefits yaitu sebesar $1,1 \%$.

4. Tingkat pengaruh keberhasilan implementasi aplikasi SIDIA berdasarkan kepuasan pengguna dengan net benefits yaitu sebesar $32,9 \%$.

5. Tingkat pengaruh keberhasilan implementasi aplikasi SIDIA berdasarkan struktur organisasi dengan net benefits yaitu sebesar $4,4 \%$.

\section{Saran}

Untuk penelitian lebih lanjut, ada beberapa saran yang mungkin dapat dipertimbangkan yaitu diharapkan pada penelitian berikutnya aplikasi SIDIA sudah diimplementasikan di tingkat unit kerja / bagian sehingga lebih banyak responden bukan hanya terbatas pada responden tingkat Perangkat Daerah namun melibatkan seluruh unit kerja / bagian di Lingkungan Pemerintah Kota Bogor, meningkatkan peran serta struktur organisasi sehingga manfaat yang diperoleh dari aplikasi SIDIA dapat dirasakan, pengunaan sistem harus lebih di tingkatkan dengan mengadakan pelatihan-pelatihan seputar penggunaan dan pemanfaatan sistem informasi agar user mempunyai keterampilan dalam menggunakan dan memanfaatkannya, menambah parameter yang belum atau perlu diperhitungkan seperti parameter lingkungan organisasi sehingga menggunakan seluruh komponen / parameter yang terdapat HOT-Fit Model, perlu diadakan penelitian lebih lanjut untuk mengetahui korelasi atau hubungan antara parameter HOT-Fit untuk evaluasi tingkat keberhasilan implementasi aplikasi SIDIA di Lingkungan Pemerintah Kota Bogor, penelitian selanjutnya dapat pula dengan menggunakan model lain sehingga dapat diperoleh bahan evaluasi implementasi aplikasi SIDIA sehingga pengembangan aplikasi SIDIA lebih optimal.

\section{DAFTAR RUJUKAN}

Arikunto, Suharsimi, 2016, Manajemen Penelitian, Jakarta: Rineka Cipta. 
Dewi, Nurpauliani dan Syaifullah. 2017. Analisis Penerapan Fire Report Online System (FROS) Menggunakan Metode HOT-Fit (Studi Kasus: PT Arara Abadi). Jurnal Ilmiah Rekayasa dan Manajemen Sistem Informasi, Vol. 3, No. 2, Agustus 2017, Hal. 87-93.

Kadarsih, Pujianto dan Muhajir Arafat. 2016. Evaluasi Digital Library AMIK AKMI Baturaja Menggunakan HOT-Fit Model. Prosiding, ANNUAL RESEARCH SEMINAR 20166 Desember 2016, Vol 2 No. 1.

Kodarisman, Raden dan Eko Nugroho. 2013. Evaluasi Penerapan Sistem Informasi Manajemen Kepegawaian (SIMPEG) di Pemerintah Kota Bogor. JNTETI, Vol. 2, No. 2, Mei 2013.

Monalisa, Siti, Presdi Ponti Anggara, dan Fitra Kurnia. 2018. Analisis Kesuksesan Penerapan Sistem Administrasi Akademik Menggunakan Human Organization Technology Fit Model. Jurnal Ilmiah Rekayasa dan Manajemen Sistem Informasi, Vol. 4, No. 1. Hal. 36-41.

Mulyadi, Dedy, Materi Perkuliahan Statistika I dan II, 2014, Sekolah Tinggi Ilmu Ekonomi Binaniaga. Bogor.

Mulyadi, Dedy, Panduan Pengolahan Data dengan SPSS 16.0, 2014, Sekolah Tinggi Ilmu Ekonomi Binaniaga. Bogor.

Neolaka, Amos, 2016, Metode Penelitian dan Statistik, Bandung: Remaja Rosdakarya. PT.

Poluan, Frincy, Arie Lumenta dan Sinsuw, Alicia. 2014. Evaluasi Implementasi Sistem E-Learning Menggunakan Model Evaluasi HOT-Fit Studi Kasus Universtias SAM Ratulangi. E-journal Teknik Informatika, Volume 4, No. 2.

Prasetyo, Bambang dan Lina Miftahul Jannah, 2016, Metode Penelitian Kuantitatif, Jakarta: Raja Grafindo Persada. PT.

Sahfitri, Vivi. 2016. Implementasi Metode HOT-Fit dalam Evaluasi Kesiapan Pengguna Sistem Informasi Akademik Terintegrasi. Jurnal BETRIK, Vol. 09, No.03.

Sarwono, Jonathan, 2012, Metode Riset Skripsi Pendekatan Kuantitatif Menggunakan Prosedur SPSS, Jakarta: Elex Media Komputindo. PT.

Sugiyono, 2015, Metode Penelitian Pendidikan Pendekatan Kuantitatif Kualitatif dan $R \& D$, Bandung: ALFABETA. CV.

Sugiyono, 2017, Metode Penelitian Kuantitatif Kualitatif dan R\&D, Bandung: ALFABETA. CV.

Viandra, Primadani, Titi Sriwahyuni dan Muhammad Anwar. 2017. Analisis Kepuasan Pengguna Aplikasi Penilaian Prestasi Kerja (SKP Online) Menggunakan Metode Human Organization Technology (HOT-Fit) pada Badan Kepegawaian Daerah Kota Padang. Jurnal Vokasional Teknik Elektronika \& Informatika Vol. 5, No. 2.

Yusof M. M, R.J. Paul dan L. K. Stergiolas. 2006. Towards a Framework for Health Information System Evaluation. Paper Read at Proceedings of the 39th Hawaii International Conferences on System Science Kauai, at Hawaii, USA. 